ward movement of the lower thorax ${ }^{1}$ results, increasing its breadth, as also the breadth of the upper abdomen. Muscle Action
Traditionally the intercostals with the diaphragm have
been accepted as primary muscles of inspiration. How-
ever, with electro-myographic research, this theory is
being questioned. The diaphragm and scalenes are now
stated to be primary muscles of inspiration replacing the
former theory, the function of the intercostals still being
warmly debated. Galen originally described the external
intercostals as inspiratory and the internal intercostals
as expiratory: others have since stated that the function
of the intercostals is postural. The postural' explanation
is that the intercostals working together maintain the
rigidity of the chest and the correct relationship of one
rib to another at any given time. This allows the primary
muscles of respiration to work without the interference
of pressure changes which could occur if the intercostal
spaces were sucked in and blown out during each
respiratory cycle. However, there is evidence of in-
aeased activity in certain intercostals at different times,
ne upper 3 pairs in quiet inspiration and the lower
intercostals in deep breathing.

As no fully accepted theory has been devised, a combination of the above opinion leads to an acceptable statement to the effect that during breathing the intercostals will contract, when required, either for pressure maintenance or to move a particular rib up or down. These functions although not of primary importance, are essential to normal respiration.

\section{Quiet Breathing}

During inspiration, scalenus anterior contracts fixing the first rib thus acting as a fixator of the upper part of the chest. The abdominal muscles fix the lower ribs and the diaphragm contracts pulling its domes and central tendon downwards on to the abdomen viscera and thus increasing the vertical diameter of the thorax.

Quiet expiration is a purely passive movement, the inspiratory muscles relax and return to their resting position, which together with the elastic recoil of the lungs cause air to be expired.

\section{Deep Breathing}

The upper part of the chest, ribs 1 and 2 , is lifted and fixed by the scalenes, the bucket-handle action of the following ribs occur with the intercostals lifting them maintaining their relationship with the first two ribs, thus both antero-posterior and lateral diameters are increased. Simultaneously the diaphragm contracts strongly, descends until the central tendon becomes fixed on the abdominal viscera, the muscle fibres continue to contract flattening the domes and lifting and spreading the lower ribs laterally and backwards. This considerably increases the lateral diameter of the thorax and upper abdomen, the upper abdominal viscera being flattened and spread sideways.

The extensors of the spine also contract in deep inspiration, flattening the thoracic curvature and opening the thorax, and so at this stage all diameters have been increased.

Forceful expiration is initiated by relaxation of all the muscles of inspiration followed by strong contraction of the abdominal muscles pulling the ribs down and increasing the intra-abdominal pressure, which forces the diaphragm up into the thorax and air is expired.

The accessory muscles of respiration, those joining the pectoral girdle to the thorax, latissimus dorsi and sternocleidomastoid are involved in forced breathing which is not a part of the normal pattern of respiration and is therefore not discussed here.

I should like to thank Professor Keen of the Anatomy Department at the University of Cape Town for his help and advice in preparing this article.
1 Grays Anatomy 35th Ed
2 J. V. Basmajian Primary Anatomy.
3 E. N. Keen-Ellis's Anatomy.
4 J. V. Basmajian Muscles Alive-Electromyography.

\title{
AN APPRECIATION
}

\section{MISS MARJORY CATT, C.S.P.}

It is with deep regret that we record the passing of Marjory Catt, one of the founder members of the South African Society of Physiotherapy. She, along with a small band of dedicated qualified physiotherapists fought for the official recognition of the profession and despite the scattered areas where physiotherapists were situated, formed what has become a substantial society with compulsory registration.

Miss Catt was born in Scarborough, England, and trained at the London Orthopaedic Hospital qualifying under the Chartered Society of Physiotherapy then known as the Chartered Society of Massage and Medical Gymnastics.

While training Miss Catt met Miss Winnie Evans from South Africa and together they formed a partnership, opening a practice in 1923. Miss Evans worked in Germiston and Miss Catt in Harley Chambers, Johannesburg. On the death of Miss Evans, Miss Catt took over the Germiston branch where she had the contract for the work of the Germiston Hospital before a Department was opened there.

Besides being an admirable and tireless practitioner,
Miss Catt devoted a great deal of her spare time and energies to the administration and development of the society. She was several times President of the Central Executive Committee - later to be the National Executive Committee of the S.A.S.P.

In recognition of her loyalty and dedication Miss Catt was made an Honorary Life Member of the S.A.S.P. on her retirement from general practice. She however, always maintained her interest in the Society and the Branch.

She attended Branch meetings and functions until her health prevented her from travelling at night. She always kept in touch with current developments.

The last official function of the Society at which Miss Catt was able to attend was the opening ceremony of the Jubilee Congress in Johannesburg in July 1975. It was a proud moment for her as she was the only one present who had been a member for fifty years and able to look back to the real beginnings of the Society.

To her sister Mrs. J. Sewell from England, her cousin $\mathrm{Mr}$. Hughes of Bedford View and other relatives and close friends we convey the sincere sympathy of the Society. We also say a very real "thank you" to Marjory Catt for her dedication and devotion to the profession and the South African Society of Physiotherapy. 